\title{
Gender Based Violence Among Pregnant Women: A Hospital Based Study
}

\author{
Chaudhary SK ${ }^{1}$, Chaudhary $\mathrm{P}^{2}$
}

\begin{abstract}
Introduction: Gender Based Violence (GBV) is prevalent and exists to some extent in virtually all societies throughout the world. Evidence shows consistent negative effect of violence on health of women particularly. This hidden disease is perceived as a social issue and not a health issue and is often overlooked by health care providers. Methodology: This study was a Cross Sectional descriptive study conducted at national Academy of Medical Science affiliated Paropaker Women's and Maternity Hospital, Kathmandu enrolling 950 pregnant women from the emergency admission room who were interviewed using structured questionnaire from mid march to the end August in the year 2007. Result and discussion: Among 950 women suffered from gender based violence (33.36\%). One hundred and fifty women faced psychological violence (47.31\%), seventy two clients faced physical violence $(22.71 \%)$, and forty two women faced sexual violence (13.24\%) and rest of them faced all types of violence. Violence was reported during the current pregnancy (41.32\%). Husbands were perpetrator of violence for almost on third of women (34.06\%), followed by mother in low (18.29\%). Joint violence by family members was quit common (28.1\%). Perpetrator outside family was responsible for approximately $20 \%$ of cases. Domestic violence was extremely common accounting for more than four fifty of cases (81.38\%). Among sexual violence, (45.45\%) women were victim of marital rape. Alcoholism as one of the common reason for wife battering, observed in this study in Maternity Hospital which is still prevalent in Nepal. Often, verbal abuse is an excuse for imposing discipline in the family. Women's economic and emotional dependence on husband could be responsible for the vulnerable status in family. Health seeking behavior following violence was found to be extremely low in this study suggestion gender based violence as a privet matter.
\end{abstract}

Key words: Prevalence gender based violence pregnancy, Nepal

\section{INTRODUCTION}

Gender Based Violence (GBV) is a public health issue and is recognized as serious violence of human right worldwide. It is an ongoing social injustice to women, Reflection an imbalance of gender based power relationship and extent of the problem is determined by social infrastructure and traditional cultural beliefs. Violence against women exists to some extent in virtually all societies throughout the worldwide, studies indicate that from $20 \%$ to over $50 \%$ of women has been beaten by an intimate male partner ${ }^{1}$ or sexually abused by an intimate oartner ${ }^{2}$. Both et all (2005) reposted a study of 10 countries and found that between $13-63 \%$ of women has experience physical violence by partner over the course of their lifetime ${ }^{3}$. An analysis in the World Bank's development report (1994), concluded that between $5 \%$ and $16 \%$ of the health year of life lost of women of reproductive age can be linked to gender based violence. Health consequences of violence can extend from physical injuries, unwanted pregnancy, gynecological problems, sexually Transmitted Diseases, miscarriage, chronic

1. Dr. Shrawan Kumar Chaudhary

2. Dr. Pushpa Chaudhary

Address for correspondence:

Dr. Shrawan Kumar Chaudhary

Department of Emergency

Nepalgunj Medical College \& Teaching Hospital

Kohalpur, Nepal

Email: shrawanchaudhary09@gmail.com pelvic pain, pelvic inflammatory diseases, self injurious behavior etc. in addition, psychological sequel could lead to depression, fear, anxiety, low self-esteem etc ${ }^{1}$.

Effect of domestic violence during pregnancy has been reported by various studies as miscarriage, insufficient weight gain, vaginal bleeding, abdominal trauma, low birth weight ruptured membranes etc. Valladares E et all (2002) reported the findings of a Hospital based case control study in Leon, Nicaragua which showed that $22 \%$ of mothers of low birth weight infants had experienced physical abuse during pregnancy by their intimate partners compared with $5 \%$ of controls. Low Birth Weight was associated with partners abuse even after adjustment of age, parity, smoking and socio economic status (OR 3.8,95\% CI 1.7,9.3) .

The study was an endeavor to identify the magnitude of the problem of gender based violence among pregnant women attending Maternity Hospital emergency. Moreover, we also tired to indentify type of violence faced by these women and their health seeking behavior.

\section{MATERIAL AND METHHODS}

This study was a cross sectional descriptive study conducted at Paropkar Women's and Maternity Hospital, Kathmandu. Sample population was selected from pregnant women admitted in this hospital. Approximately 950 women who were admitted at or after 20 weeks of gestation who did not require urgent medical attention were enrolled in the study from the 
emergency admission room and interviewed in a pre specified room where confidentiality and privacy was ensured. They were also given the choice to withdraw from the interview if they did not feel comfortable.

Data were entered into a structured questionnaire by research assistant by client interview. Variables recorded were Demographic characteristic-Age, marital status, Area of residence, Education, Socio-Economic status, Caste and ethnicity, History of physical abuse, sexual abuse and psychological abuse together with time of assault, frequency and perpetrator, Health care seeking attitude and Attitude of health care providers if they seek help and support.

Data were collected from mid March to end of August, 2007 i.e. for a period of five and half month Data were analyzed by frequency distribution curve, number and percentage. Data entry and analysis was done manually.

\section{RESULTS}

There were nine hundred and fifty women who met the inclusion criteria and gave consent for the interview. Approximately 540 women who met the inclusion criteria but declined to participate in the study of personal reason. Out of total obstetric admissions, $12.20 \%$ of case wear enrolled in the study. Among 950 women, 317 women suffered from gender based violence (33.36\%) Four hundred and sixty women were aware or had heard about gender based violence $(48.42 \%)$ whereas four hundred ninety women had not heard the wordgender based violence (51.57\%).

\section{Demographic Profile of clients who faced gender based violence}

Majority of women (57.72\%) belonged to $20-29$ years of age group ( $n=183)$. Women who faced GVB were either were illiterate $(n=88)$, had primary level of education $(n=107)$ or secondary level of education (24.44\%). Only thirty five of them were graduate and above (11.04\%). Illiterate women faced physical violence relatively more $(51.38 \%)$ that psychological (20.40\%) and sexual violence (27.27\%). Educated women faced relatively more psychological violence $(12.75 \%)$ that physical (6.94\%) or sexual (9.09\%).

Majority of women who faced violence were of middle socio economic class $(43.53 \%)$ compared to low socio economic group (17.98\%), low middle socio economic group (28.39\%), or upper middle class (10.09\%). The same pattern was observed in those women who faced psychological violence but physical violence was less commonly seen in women who belonged to upper middle class (4.16\%). It is interesting to note that relatively more women who faced sexual violence belonged to either low socio-economic class (18.18\%) or low middle socioeconomic class (36.36\%) compared to women who belonged to middle socio-economic class $(31.81 \%)$ or upper middle class. Sixty three women were Brahmins by caste (19.87\%), eighty eight women were Chhetri (27.76\%), seventy women were Newar (22.08\%), seventeen women were Sherpas (5.36\%), eighteen were Tamang (5.67\%) and others comprised of sixty one women (19.24\%).

\section{Type of violence faced by client}

Among 317 women who faced violence at some stage of their lives, one hundred and fifty women's faced psychological violence $(47.31 \%)$, seventy two clients faced physical violence $(22.71 \%)$, and forty two women faced sexual violence (13.24\%). Thirty five of them suffered both physical and psychological violence (11.04\%), sever of them suffered from physical and sexual violence $(2.20 \%)$, six of them faced both sexual and psychological violence (1.89\%), whereas five women suffered from all three kinds of violence i.e. Physical, Sexual and Psychological violence(1.57\%).

\begin{tabular}{|l|c|c|}
\hline Type of violence faced by clients & No. & \%age \\
\hline Physical & 72 & $22.71 \%$ \\
\hline Sexual & 42 & $13.24 \%$ \\
\hline Psychological & 150 & $47.31 \%$ \\
\hline Physical and Psychological & 35 & $11.04 \%$ \\
\hline Physical and Sexual & 7 & $2.20 \%$ \\
\hline Sexual and Psychological & 6 & $1.89 \%$ \\
\hline All kinds & 5 & $1.57 \%$ \\
\hline Total & 317 & $99.96 \%$ \\
\hline
\end{tabular}

Table I: Showing types of violence faced by women

\section{Time of violence}

Hundred and thirty one women reported that they are facing violence as ongoing day to day problem within the last month i.e. during the current pregnancy (41.32\%), one hundred and forty one women faced within last year (44.47\%), whereas forty five women has experience of violence more than a year ago (14.19\%).

\section{Frequency of Violence}

Hundred and twenty five women said that facing violence was occasional or one off problem (39.43\%), whereas hundred and ninety two women were facing regularly $(60.56 \%)$.

\section{Perpetrator of violence}

Hundred and eight women revealed that their husband were perpetrator of violence (34.06\%), mother in law was perpetrator for fifty eight women (18.29\%), four of them were victims of violence by their father in low (1.26\%), whereas others such as neighbors/ relatives/ school teaches etc. were perpetrators for sixty two of them (19.55\%). Twenty eight of them were victim of violence by the husband and mother in law joint $(8.83 \%)$. Twenty three of them were victimized by both mothers in law and father in law (7.25\%). Rest of them was 
sufferer of domestic violence by other family members. Women who faced psychological violence. Perpetrators were mostly husband -for forty five women (22.9\%), mother in law for thirty seven women (18.87\%), and husband an mother in law were joint perpetrator for twenty women (10.20\%), and other were tortured jointly by family members. For thirty nine women, perpetrator was others such as neighbors, villagers, employers at office etc. (19.89\%). Beating by husbands was common (54.43\%). For twenty women, perpetrate were other such as neighbors, villages, school teachers, employers particularly boss at office etc. (25.31\%) Regarding sexual violence, Perpetrators were husband for twenty women (45.45\%), who were forced to sexual relationship against their wishes, and others were victims of sexual assault including rape by employer/neighbors/boyfriends/school teachers etc (54.54\%).marital rape was not uncommon during menstruation, pregnancy or immediate postpartum.

\begin{tabular}{|l|c|c|}
\hline Perpetrator of Violence & No. & $\%$ \\
\hline Husband & 108 & 34.06 \\
\hline Mother in low & 58 & 18.29 \\
\hline Father in low & 4 & 1.26 \\
\hline Husband and Mother in law & 28 & 8.83 \\
\hline Mother and Father in law & 23 & 7.25 \\
\hline Husband and other family members & 26 & 8.19 \\
\hline Husband and Father in law & 8 & 2.52 \\
\hline Others & 62 & 19.55 \\
\hline Total & 317 & 99.95 \\
\hline
\end{tabular}

Table II: Showing perpetrators of violence

\section{Place of violence}

Two hundred and fifty eight women faced violence exclusively at home $(81.38 \%)$, whereas fifty nine of them were victims at work place or other places (18061\%).

\section{Health seeking behavior following violence}

Among 317 victims of violence, only twenty eight women visited health facility (8.83\%) usually following serious physical injuries, but only five of them disclosed the type an cause of violence to the health care providers(17085\%). None of the victims who victims health facility said that doctors /health care providers asked them the detail of the incident and they were satisfied with the health care providers in addressing their needs.

\section{DISCUSSION}

Out of 950interviews, 317 participants suffered from gender based violence (33.36\%) i.e. approximately one third of pregnant women who were enrolled in the study. This could be underestimation of the magnitude of problem as approximately 540 women who met the inclusion criteria declined to participate in the study.
Violence during pregnancy is so common that warrants screening during prenatal care though prevalence varies widely in different part of the world.78 M Mbokata and J moodley (2003)Reported prevalence of abuse of around 35\% during current pregnancy among pregnant women attending a public sector hospital in Durban, South Africa and physical abuse being most common $(52 \%)^{9}$. This figure is quite comparable to the prevalence rate in our study, so as the other figure reported by Sahin HA and Sahin HG (2003) Who found a prevalence of domestic violence (physical and sexual abuse) of around 33.3\% among pregnant women in Turkey ${ }^{10}$. Studies in South Asia suggests that a significant proportion of women are physically abused during pregance $e^{5,11,12}$.

It is noticeable that approximately $15 \%$ of women in this study were adolescents facing Violence and their consequences. It seems that relatively more women were affected by sexual violence in their age ground of $20-29$ Years (61.36\%) and this group also reflects young married population subjected to marital rape as well as non partner sexual assault at work place. Studies have shown that demographic factors such as age, number of living male children, and extended family residence are inversely associated with risk of domestic violence.

Low socioeconomic status as one of the strongest predictors of violence prior to pregnancy was reported by Castro R, Peek-Asa C, Ruiz $A(2003),{ }^{13}$. The strongest predictors of abuse were violence prior to pregnancy, low socioeconomic status, parental violence witnessed by women in childhood and violence in the abusive partner's childhood in this study. The probability of violence during pregnancy of women experiencing all of these factors was $61 \% .^{13}$ higher socioeconomic status levels and higher levels of education among women have generally been found to be protective factors against women's risk of domestic violence. ${ }^{14}$ Jewkes $R$, Levin J, Penn-Kekana L(2002) reported findings of south African cross sectional study enrolling 1306 women and concluded that domestic violence is most strongly related to the status of women in a socity. ${ }^{15}$ It seems that widespread poverty and illiteracy with patriarchal South Asian society is related to the status of women putting them at risk of domestic violence.

Who multi center study reported wide variation in prevalence and different types of violence across the different countries. The proportion of ever-partnered women who had ever experienced physical and sexual violence, or both, by an intimate partner in their life time, ranged from $15 \%$ to $71 \%$ with most sites falling between $29 \%$ to $62 \%$. Women in Japan were the least likely to have ever experienced physical or sexual violence, or both, by an intimate partner, whilst the greatest among of violence was reported form Bangladesh, Ethiopia and Tanzania. Similarly other studies also reported wide variation in different populations.

Intimate partner violence particularly sexual coercion has been 
consistently reported by various studies. Bradley $\mathrm{F}$ et al Reported findings of Cross Section Survey of Women Attending General Practice that revealed that 39\% (95\% confidence interval $36 \%$ to $41 \%$ ) had experienced violent behavior by a partner. Romito P, Gerin D (2002) reported a high prevalence of different kinds of violence amouMng 510 women; mostly perpetrated by men well know to the victim, $10.2 \%$ had experienced physical/sexual violence in the last 12 months, regardless of perpetrator.

Physical and Sexual abuse by family members other then partner contributes to significant member of cases. Torture and beating by husband and in laws particularly mother in law was found to be very common. In Nepal, joint family system is still prevalent and daughter in low plays a subordinate role expected to maintain every norm and standard of the family. Often, verbal abuse in as excuse for imposing discipline in the family. Amaju (Husband's elder sister) is very powerful member of the family and verbal abuse/torture by Amaju is not uncommon in Nepalese family. Women's economic dependence on husband and emotional insecurity for herself and her children could be responsible for the vulnerable status of wives putting them at risk to abuse by husband and his family.

Sexual violence within marriage is also common as shown in this study. A significant percentage of husbands reported having committed on or more episodes of physical violence (25.1\%) or sexual violence (30.1) against their wives during the preceding year. Significantly higher risk of recent physical violence was also evident among the subgroup of husbands who reported having had an extramarital relationship in the study. This may reflect the widely held view across much of Indian society the it remains the husband's right to physically compel his wife the engage in sexual relation when desired. Health seeking behavior following violence was found to be extremely low in this study as women though that abuse is a private matter and there is no need to discuss with others. These findings reflect that awareness about gender based violence among health care providers is poor and they failed to address this hidden problem among women who visited their health facility. Similar findings were also reported by other studies.

Alcoholism as one of the common factor responsible for wife battering was observed in this study. Male alcoholism as a risk factor for wife bettering was also reported by Koenig MA et al From Uganda. There were only six women who said that they are tortured by husband and in laws as dowry not adequate at the time of marriage (3.06\%). Women role as subordinate the men put her at risk of traditional forms of violence such as wife battering and sexual assault, dowry crimes such as bride burning etc. Dowry system is not very common in Nepalese community but quite common among people from border area close to India in marriage across the border. Victimization due to insufficient dowry is very common in neighboring country, India in South Asian Countries, low social status of women, rigid cultures and patriarchal attitudes which devalue the role of women, result in the wide spread occurrence of violence against women.

\section{CONCLUSION}

1. Gender base violence is quite common in pregnant women attending Paropakar Maternity and Women's Hospital.

2. Awareness about Gender based violence is low.

3. Psychological violence in form of verbal abuse/torture/isolation is the commonest type of violence faced by these women. Physical violence was second common followed by sexual violence.

4. Violence by husband accounted for approximately one third of cases. Family members particularly in laws victimize women jointly.

5. Violence at home accounted for almost four fifth of gender based violence.

6. Many women are facing violence regularly even during pregnancy.

7. Alcohol addiction is intimate partner accounts for physical as well as psychological violence.

8. Marital rape is common contributing to almost fifty percent of sexual violence.

9. Health seeking behavior following violence is very low unless there is significant physical injury.

\section{RECOMMENDATIONS}

1. Screen for gender base violence in booking visit preferably using a check list during ANC.

2. Sensitize health care providers of various cadre to indentify and manage gender based violence as health issue and not just as social issue.

3. Use reproductive health services as entry points for identifying and supporting women affected by gender based violence.

4. Develop a protocol for care and support of women detected to have suffered from gender based violence.

5. Ensure privacy and confidentiality for clients based on human rights approach who are affected by gender based violence.

6. Develop mechanism for clean documentation and record keeping.

7. Establish a social support unit at hospital to help and provide necessary counseling and support for these women and their families.

8. Establish linkage with legal system and community based organizations to address the need of these women.

9. Ensure follow up mechanisms for care and support to women affected by gender based violence.

10. Encourage more research or areas such as causes of violence, health consequences on mother and newborn and cost of care of these women. 


\section{ACKNOWLEDGEMENT}

Al would like to acknowledge the authority of Institution Review Board of Nepal academy of Medical Science and the WHO for approving the proposal and providing financial support. I would like to extend thanks to the authority of Paropkar Maternity and Women's hospital and members of research team- Mrs. Shanti Vaidya, Mrs. Jaya Poudel and Miss Sharmila Shakya for helping to conduct this study.

\section{REFERENCES}

1. Lori L Heise, Jacqueline Pitanguy, Adrieen Germain. Violence against women : The hidden health problem (no 255 world bank discussed paper) Washingtom DC. World bank 1994.

2. Krug EG et al: eds World report on violence and health. Geneva W H O.2002. a 20 i l a b le a t (www.who.int/violence.injury.pervention/violence/woeld/repo rt/introduction/pdf).

3. Bott Sarah, Andrew Morrieson and Mary Ellsberg. Preventing and responding the Violence Against Women in middle and low income counties: A global review and analysis, World Bank Policy Research Working paper 3618, the World bank, Washington, DC, June, 2005

4. National Human Rights commission. Human rights in Nepal. A summary report 2003 Publisher-National Human Rights commission Nepal.

5. UNICEF 2001a. A reference kit on violence against women and girls in South Asia. Kathmandu:UNICER.ROSA

6. Valladares E, Ellsberg M. Pean R, Hogberg U, Persson LA. Physical Partner Abuse During Pregnancy: A Risk Factor for Low Birth Weight in Nicaragua Obstet Gynecol.2002:100:700-705.

7. Campbell J, Garcia-Mareno C, Sharps P. Abuse during pregnancy in industrialized and developing countries. Violence against Women. 2004;10(7):770-789.

8. Richardson J, Coid J, Petruckevitch A, et al Identifying Domestic Violence: Sectional Study in Primary Care BMJ.2002;324:274.

9. Mbokata M; Moodley J, Domestic Abuse. An antenatal survey at King Edwards VIII Hospital, Durban S Afr Med J. 2003;93:455-457.

10. Sahin HA, Sahin HG. An Unaddressed Issue: Domestic Violence and Unplanned Pregnancies Among Pregnant Women in Turkey Eur J Contracept Reprod Health Care. 2003:8:93-98.

11. Violence against women is South Asia- A regional analysis (UNFPA report.2003).

12. ICRW.1999a. Physical and psychological domestic abuse : A multi side survey in India. Report in brief, International Center For Research on Women(ICRW). The Center for Development and population Studies (CEDAP). Promoting Women in Development.

13. Castro R. Peek-Asa C,Ruiz A. Violence Against Women in Mexico: A Study of Abuse Before and During Pregnancy AM J Public Health. 2003;93:1110-1116.

14. Michael A. Koenig, Rob Stephenson, Saifuddin Ahmed, Shireen J, Jejeebhoy, and Jacqueiyn Campbell (2005). Individual and Contextual Determinations of Domestic Violence in North India C: \Documents and Settings \prefectpic \Desktop \gender violence $\backslash$ Individual and Contextual Determinants of Domestic Violence in North India - Koenig et al_96 (1) 132-- American Journal of Public Health.htm.

15. Jewkes R, Levin J, Penn-Kekana L Risk Factors For Domestic Violence: Findings From A South Africa Cross-Sectional Study Soc Sci Med. 2002;55:1603-1617.

16. WHO Multi Country Study on Women's Health And Domestic
Violence Against Women Summary report of initial result of prevalence, health outcomes and women's responses. WHO.20005.

17. Kristin L, Dunkle, Rachel K. Jewkes, Heater C. Brown, Mieko Yashihama, Glenda E. Gray, James A. Mclntre and Sioban D. Harlow. Prevalence and Patterns of Grnder-based Violence and Revictimization among Women Attending Antenatal Clinics in Soweto, South Africa American Journal of Epidemiology 2004 160(3):230-239.

18. Wijma B, Schei B, Swahnberg K, et al Emotional, Physical and Sexual Abuse in Patients Visiting Gynecology Clinics: A Nordic Cross-Sectional Study Lancet.2003jun21;361:2107-2113.

19. Stenson K, Heimer G, Lundh C, Nordstrom ML, Wenker A Lifetime Prevalence of Sexual Abuse in a Swedish Pregnant Populatiin Acto Obset Gynecol Scand. 2003;82:529-536.

20. Fisher M, Yassour-Borochowitz D, Abuse in Pregnancy :Rusult From a phone Survey in Northern Israel Isr Med Assoc J. 2003;5:35-39.

21. Bradley F, Smith M, Long J, O'Dowd T Reported Frequency of Domestic Violence: Cross Sectional Survey of Women Attending General Practice BMJ.2002;324:271.

22. Romito P, Gerin D Patients About Violence: A Survey of 510 Women Attending Social and Health Services in Trieste, Italy Soc Sci Med. 2002;54:1813-1824.

23. Peschers UM, Du Mont J, Jundt K et al Prevalence of Sexual Abuse Among Women Seeking Gynecologic Care in Germany Obset Gynecol. 2003;101:103-108.

24. Koenig MA, Lutalo $T$, Zhao $F$, et al Violence in Rural Uganda: Evidence From a Community-Based Study Bull Would Organ. 2003;81:53-60. Epub 2003 Mrar 11.

25. Niaz U Violence Against Women in South Asian Countries Arch Women Ment Health 2003;6:173-184. 